\title{
Relation of cervical glandular intraepithelial neoplasia to microinvasive and invasive adenocarcinoma of the uterine cervix: a study of 121 cases
}

K Kurian, A Al-Nafussi

\begin{abstract}
Aims-To examine the relation between invasive adenocarcinoma and its alleged precursor, cervical glandular intraepithelial neoplasia (CGIN), and to assess the management and outcome of CGIN and the validity of using the term "microinvasive adenocarcinoma."
\end{abstract}

Methods-The clinical and pathological features of 121 cases of glandular neoplasia of the cervix diagnosed between the years 1990 to 1995 were examined for the following: histological diagnosis, smear records, type of treatment, the association between the precursor lesions and invasive disease, and follow up.

Results -27 cases were identified as low grade CGIN (L-CGIN) and 38 as high grade CGIN (H-CGIN), 10 as microinvasive adenocarcinoma (less than $5 \mathrm{~mm}$ in depth), and 46 as invasive adenocarcinoma. The ratio of non-invasive to invasive disease was 1.12:1. The mean age of women was $39,43,43$, and 48 years for L-CGIN, H-CGIN, microinvasive, and invasive adenocarcinoma, respectively. L-CGIN was seen in $13 \%$ and $18 \%$ of H-CGIN and microinvasive disease, respectively. H-CGIN was seen in $100 \%$ of microinvasive and $26 \%$ of invasive adenocarcinomas. The available smears before diagnosis predicted $59 \%$ of L-CGIN, $70 \%$ of H-CIGN, $100 \%$ of microinvasive adenocarcinoma, and $32 \%$ of invasive adenocarcinomas. Treatment of $74 \%$ of L-CGIN, $52 \%$ of $\mathrm{H}-\mathrm{CIGN}$, and $\mathbf{1 0 \%}$ of microinvasive adenocarcinoma was by diathermy loop excision only. The remaining cases had hysterectomy. Residual disease was found in $43 \%, 50 \%$, and $33 \%$ of hysterectomies for L-CGIN, H-CGIN, and microinvasive adenocarcinoma, respectively. This is correlated with positive margins, or disease within $3 \mathrm{~mm}$ of margins on loop specimens. Cervical smear follow up for two to seven years revealed no recurrence of glandular lesions in any of the cases of CGIN or microinvasive adenocarcinoma. Conclusions-Precursor glandular lesions tend to progress to invasive carcinoma. There is a progressive increase in age of patients from L-CGIN to invasive disease, a span of approximately 10 years. There is a high association between H-CGIN and invasive disease. In the management of such alleged precursors, it is important to ensure adequate free margins of at least 3 mm. Microinvasive adenocarcinoma appears to have an excellent prognosis if treated by hysterectomy.

(F Clin Pathol 1999;52:112-117)

Keywords: cervix; cervical glandular intraepithelial neoplasia; microinvasive adenocarcinoma; adenocarcinoma

In the last few decades adenocarcinomas have formed an increasing proportion of cervical neoplasms. This proportion has risen from 5\% in the 1950 s to $10-22 \%$ in the mid-1990s..$^{1-4}$ With this increase, more precursor lesions are being seen. The latter fall into a morphological spectrum ranging from mild to severe abnormalities, best referred to as cervical glandular intraepithelial neoplasia (CGIN).$^{5-7}$ Unlike its squamous counterpart (cervical intraepithelial neoplasia, CIN, as used in the United Kingdom), CGIN has been divided into low grade lesions (glandular dysplasia; L-CGIN) and high grade lesions (adenocarcinoma in situ, H-CGIN). ${ }^{8-15}$ This is more akin to the Bethesda classification of squamous intraepithelial lesions (SIL).

Information regarding incidence, natural history, and the relation between the alleged precursor lesions and invasive adenocarcinoma has been limited. A few studies have shown that women with H-CGIN are 10 to 20 years younger than those with invasive disease ${ }^{14} 16$ and that invasive adenocarcinoma and CGIN commonly coexist in the same specimen. ${ }^{17} 18$ The natural history of L-CGIN is even less clear. Brown and Wells ${ }^{8}$ have found that progression from low to high grade lesion could take place in 1.5 to 3 years. It has also been suggested that women with L-CGIN are at increased risk of further preinvasive glandular changes in the genital tract. ${ }^{19-21}$

Another difficulty concerning glandular neoplasia of the cervix is the controversial terminology of microinvasive adenocarcinoma, its natural history, and its histological recognition. ${ }^{6223}$ The few reports that have recently appeared regarding microinvasive adenocarcinoma have defined the tumour as invading up to $5 \mathrm{~mm}$ from the surface of the lesion and to have an excellent prognosis, similar to its squamous counterpart. ${ }^{62-27}$ The first sign of stromal invasion is identified when H-CGIN shows an abrupt glandular change, the cells becoming enlarged with abundant eosinophilic, squamoid-like cytoplasm. ${ }^{22} 2328$
Accepted for publication 11 August 1998 


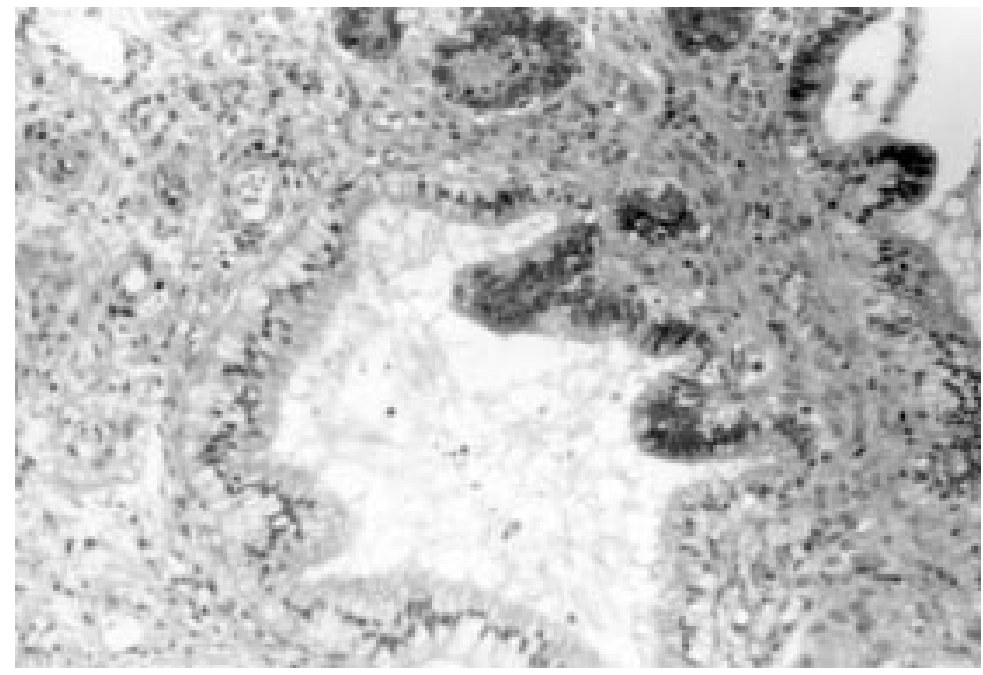

Figure 1 Low grade CGIN showing abrupt transition between the normal endocervical and the dysplastic epithelium. Notice nuclear enlargement and stratification with loss of mucin secretion. $(H \mathcal{E} E \times 11$.)

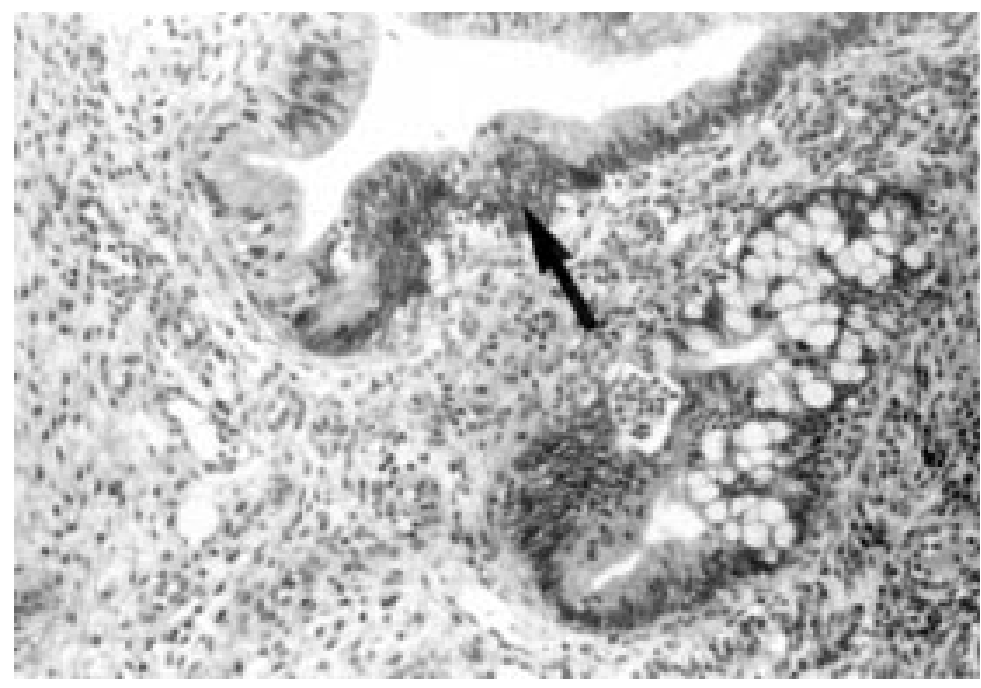

Figure 2 Low grade CGIN in upper gland (arrow) with neighbouring area showing high grade CGIN with goblet cell metaplasia.

This appearance corresponds to stage $1 \mathrm{~A} 1$ of the 1986 International Federation of Gynecology and Obstetrics (FIGO) definition. ${ }^{29}$ More advanced invasive changes become measurable in two or three dimensions, corresponding to the 1986 FIGO stage 1A2. In this case the gland usually develops a marked cribriform pattern and appears more crowded and neoplastic, often with a clear stromal response extending beyond the normal crypt field. It may also show a solid or papillary growth pattern, but within a depth of $5 \mathrm{~mm} .{ }^{23}$ However, there is very little information on the incidence of microinvasive adenocarcinoma and its relation to $\mathrm{H}-\mathrm{CIGN} .^{25}$

Although the cytological features of CGIN have been established, ${ }^{6} 111530$ the diagnostic sensitivity of the cervical smear test is still less than for its squamous counterpart. This is especially so in the presence of a coexisting squamous lesion. ${ }^{8} 931$

Finally there is an ongoing problem in management of CGIN and microinvasive adenocarcinoma. High grade CGIN has been variously treated by hysterectomy or cone excision of the cervix. ${ }^{5693233}$ Residual disease following cold knife conisation with negative margins for adenocarcinoma in situ has been also reported..$^{52} 33$ Microinvasive adenocarcinoma has been successfully treated by cold conisation or hysterectomy, like its squamous counterpart. ${ }^{23} 25$ However, pelvic recurrence following radical hysterectomy has been documented. ${ }^{25}$

In our department we receive approximately 90000 cervical smears and 2500 to 3000 cervical loop excisions annually. We have been encountering glandular neoplasms of the uterine cervix with increasing frequency. The aim of this study was to carry out a retrospective review of the experience of the pathology department, Edinburgh University, with respect to these lesions. In particular, we wished to address the unresolved question of the relation between invasive adenocarcinoma and its alleged precursor lesions, to assess the management and outcome of CGIN, and to consider the validity of the use of the term "microinvasive adenocarcinoma."

\section{Methods}

PATHOLOGICAL ASSESSMENT

The computerised files of the pathology department, Edinburgh University, were searched from January 1990 to December 1995 to identify all cases diagnosed with glandular dysplasia, adenocarcinoma in situ, and invasive adenocarcinoma. The reviewed material included diathermy loop excisions of the uterine cervix and hysterectomy specimens. These were Bouin or formalin fixed, and the cervices were circumferentially cut into $8-17$ blocks. The sections were stained with haematoxylin and eosin (H\&E). These were reviewed for the presence of low and high grade CGIN, evidence of early or frank invasion, and any associated CIN. The lesions were considered multifocal if they affected different sites along the endocervical canal or if they were separated by at least $3 \mathrm{~mm}$ of normal endocervical epithelium.

The histological criteria used were based on those previously described. ${ }^{6} 81215$

LOW GRADE CGIN

The features are illustrated in figs 1 and 2. The key cytological features for the diagnosis of L-CGIN were:

(1) An abrupt junction between normal and abnormal glandular epithelium.

(2) Loss/reduction of cytoplasmic mucin.

(3) Minimal pseudostratification.

(4) Nuclear atypia - that is, enlargement, hyperchromasia, fine to moderate granular chromatin.

(5) Evidence of cellular turnover-that is, apoptotic bodies and or occasional mitoses (less than one or two per glandular grouping).

Architectural features included:

(1) Glandular crowding.

(2) A minor degree of branching and budding and an occasional intraluminal papillary projection (low grade CGIN does not show a cribriform growth pattern). 


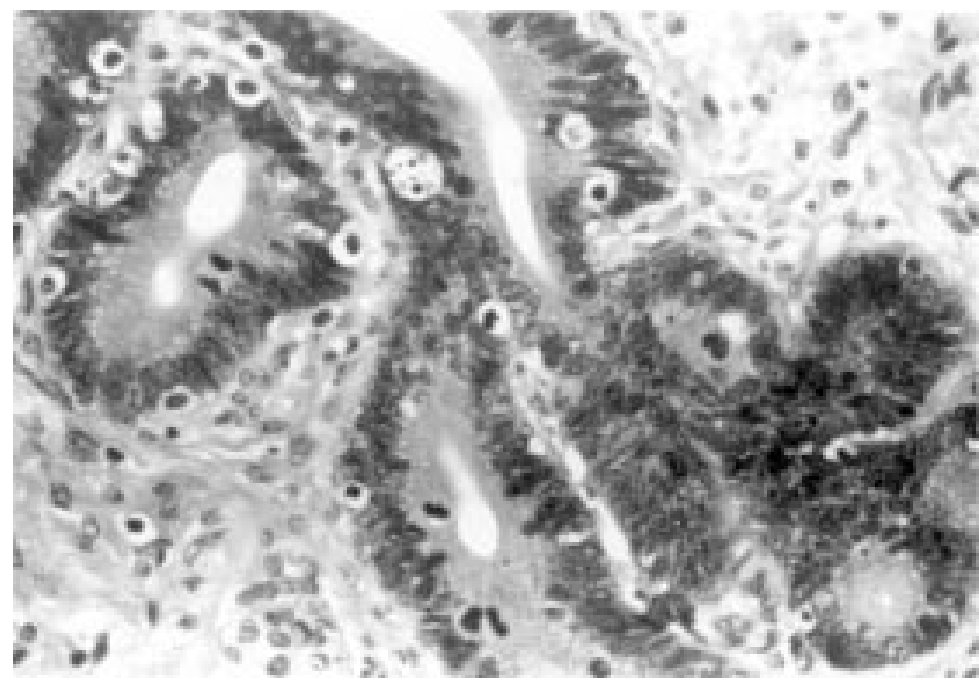

Figure 3 High grade CGIN showing crowded glands lined by cells with enlarged nuclei with some stratification, mitotic figures, and apoptosis. (HE्E $E \times 27$.

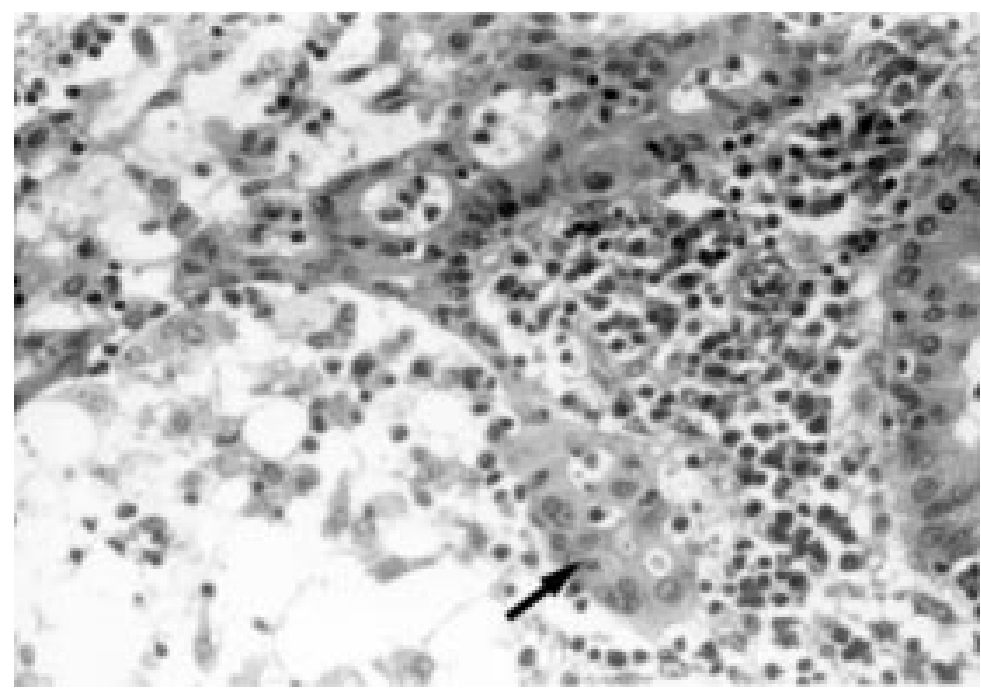

Figure 4 Buds of early stromal invasion (arrow). Notice the gland with a cribriform pattern and a tongue of glandular cells showing squamoid change with an inflammatory response. $(H \mathcal{E} E \times 27$.) according to the criterion mentioned abovethat is, invasion of the stroma to $5 \mathrm{~mm}$ or less. This was measured from the nearest piece of abnormal glandular epithelium lining either the cervical canal or an endocervical gland. The depth of invasion was measured using a calibrated ocular micrometer.

FRANKLY INVASIVE ADENOCARCINOMA

The diagnosis of frankly invasive adenocarcinoma was based on morphological grounds without the use of any special stains. Adenosquamous carcinomas were excluded for the purpose of the study.

SMEAR HISTORY

The smear histories of all women were obtained from our departmental computer records. These included at least two preceding smears and two to seven follow up smears.

\section{CLINICAL DATA}

The age of the patients, methods of treatment, and the presence or absence of residual disease were obtained from our departmental records.

\section{Results}

Clinical details of the patients are given in table 1 . There were 121 patients with glandular neoplasia of the cervix. Twenty seven were L-CGIN, 38 H-CGIN, 10 microinvasive, and 46 had invasive adenocarcinoma.

Eight of the microinvasive cases were FIGO stage 1A1 (less than $3 \mathrm{~mm}$ depth), with an average depth of $2.76 \mathrm{~mm}$, and two were stage $1 \mathrm{~A} 2$ (depth of $3-5 \mathrm{~mm}$ ), with an average of 4.2 $\mathrm{mm}$.

The mean age of the patients increased from 39 years for L-CGIN (range 26 to 67 years), to 43 years for both $\mathrm{H}-\mathrm{CGIN}$ and microinvasive adenocarcinoma (range 22 to 77 years and 33 to 60 years, respectively), to 48 years for invasive adenocarcinoma (range 34 to 75 years).

Cervical smears were taken before diagnosis in $70 \%$ of L-CGIN cases (19 of 27), $76 \%$ of H-CGIN cases (29 of 38), and in all 10 cases of microinvasive carcinoma. Among these, glandular abnormality was predicted in $59 \%$ of L-CGIN cases (eight glandular abnormality and three mixed lesion), $70 \%$ of H-CGIN cases ( 15 glandular abnormality and five mixed lesion), and $100 \%$ of microinvasive adenocarcinoma cases. The remaining smears predicted squamous abnormality only.

Thirty per cent of L-CGIN cases and $24 \%$ of H-CGIN cases were discovered incidentally at loop excision for CIN or at hysterectomy for benign lesions. Of the invasive adenocarcinomas, $55 \%$ were symptomatic, $32 \%$ were screen detected, $7 \%$ were discovered at loop excision for squamous dyskaryosis, and $6 \%$ were beyond the screening age group of 65 years. Twenty eight percent of L-CGIN cases and $26 \%$ of H-CGIN cases were multifocal.

The association between precursor lesions and invasive disease is seen in table 2. High grade CGIN was seen in all cases of microinvasive adenocarcinoma (95\% confidence interval (CI) $69 \%$ to $100 \%$ ) and in $26 \%$ of invasive disease (95\% CI $13 \%$ to $40 \%)$. Low grade CGIN
MICROINVASIVE ADENOCARCINOMA

The features are shown in fig 4 . The diagnosis of microinvasive adenocarcinoma was made 
Table 1 Data on 121 cases with glandular neoplasia of the cervix

\begin{tabular}{lllll}
\hline & L-CGIN & H-CGIN & $\begin{array}{l}\text { Microinvasive } \\
\text { adenocarcinoma }\end{array}$ & $\begin{array}{l}\text { Frankly invasive } \\
\text { adenocarcinoma }\end{array}$ \\
\hline $\mathrm{n}$ & 27 & 38 & 10 & 46 \\
Mean age (years) & 39 & 43 & 43 & 48 \\
Smears within 3 years of diagnosis & $70 \%(19 / 27)$ & $76 \%(29 / 38)$ & $100 \%(10 / 10)$ & $44 \%(20 / 46)$ \\
Abnormal glandular cells on smear & $59 \%(11 / 19)$ & $70 \%(19 / 29)$ & $100 \%(10 / 10)$ & $32 \%$ \\
Found incidentally in LLETZ/hysterectomy & $30 \%$ & $24 \%$ & $0 \%$ & $7 \%$ \\
Associated CIN & $55 \%$ & $47 \%$ & $40 \%$ & $11 \%$ \\
Treated by LLETZ & $74 \%$ & $52 \%$ & $10 \%$ & $73 \%$ \\
Residual disease in hysterectomy & $43 \%$ & $50 \%$ & $33 \%$ & $17 \%$ \\
Recurrent abnormal glandular cells on follow up & $0 \%$ & $10 \%$ & $0 \%$ & \\
\hline
\end{tabular}

CIN, cervical intraepithelial neoplasia; H-CGIN, high grade cervical glandular intraepithelial neoplasia; hyst, hysterectomy;

L-CGIN, low grade cervical glandular intraepithelial neoplasia; LLETZ, large loop excision of transformation zone.

was seen in $13 \%$ of cases of $\mathrm{H}-\mathrm{CGIN}(95 \% \mathrm{CI}$ $3 \%$ to $28 \%$ ) and in $18 \%$ of cases of microinvasive adenocarcinoma ( $95 \%$ CI $2 \%$ to $52 \%$ ).

Associated CIN was found in 16 of 29 cases of L-CGIN ( $55 \%$ ), 18 of 38 cases of H-CIGN $(47 \%)$, four of 10 cases of microinvasion, and five of 48 cases of invasive adenocarcinoma (11\%).

Twenty of 27 cases of L-CGIN (74\%), 20 of 38 cases of H-CGIN ( $52 \%)$, and one of 10 cases of microinvasive adenocarcinoma were treated by diathermy loop excision of cervix only, and the remaining cases were treated by hysterectomy. Seventy one per cent of cases of invasive adenocarcinoma were treated by hysterectomy, with or without radiotherapy, and the remaining cases were treated by radiotherapy alone.

Residual disease was present in $43 \%, 50 \%$, $33 \%$, and $73 \%$ of hysterectomies for L-CGIN, H-CGIN, microinvasive adenocarcinoma, and invasive adenocarcinoma, respectively. This correlated with positive margins, or disease within $3 \mathrm{~mm}$ of margins on loop specimens. Only one case of H-CGIN with negative margins on loop excision showed residual disease on hysterectomy.

Follow up for two to seven years by cervical smears (number of smears ranging from four to nine) showed subsequent glandular abnormality in $10 \%$ of high grade lesions treated by loop excision only. No glandular recurrence was seen in any of the microinvasive adenocarcinomas. However, $90 \%$ of these cases were treated by hysterectomy. In addition, $17 \%$ of surviving women with invasive adenocarcinoma showed glandular abnormalities on cervical smear. Smears suggesting CIN were found in $15 \%$ of L-CGIN and 2\% H-CGIN cases; normal results were reported in the remainder.

\section{Discussion}

Our study supports the view that CGIN is a precursor of invasive adenocarcinoma. ${ }^{614} 1621$ The mean age of women progressively increased from 39 years for L-CGIN, to 43 years

Table 2 Association between low grade cervical glandular intraepithelial neoplasia (L-CGIN), high grade cervical glandular intraepithelial neoplasia (H-CGIN), microinvasive adenocarcinoma, and invasive adenocarcinoma

\begin{tabular}{lllll}
\hline & L-CGIN H-CGIN & $\begin{array}{l}\text { Microinvasive } \\
\text { adenocarcinoma }\end{array}$ & $\begin{array}{l}\text { Frankly invasive } \\
\text { adenocarcinoma }\end{array}$ \\
\hline $\mathrm{n}$ & 27 & 38 & 10 & 46 \\
Mean age (years) & 39 & 43 & 43 & 48 \\
Associated L-CGIN & & $13 \%(3 \%$ to $28 \%)$ & $18 \%(2 \%$ to $52 \%)$ & $0 \%(0 \%$ to $8 \%)$ \\
Associated H-CGIN & & & $100 \%(26 \%$ to $100 \%)$ & $26 \%(13 \%$ to $40 \%)$ \\
\hline
\end{tabular}

The $95 \%$ confidence intervals for percentages are given in parentheses. for both H-CGIN and microinvasive adenocarcinoma, and 48 years for adenocarcinoma, a span of approximately 10 years. The difference in mean age, however, between H-CGIN and frankly invasive disease was only five years. This concurs with previous studies showing CGIN preceding invasive adenocarcinoma by an interval ranging from two to eight years. ${ }^{141718}$ Other studies have shown that women with H-CGIN are 10 to 20 years younger than those with invasive adenocarcinoma. ${ }^{81416}$ The natural history of L-CGIN is poorly documented. Only a few studies have compared the mean age of patients with glandular dysplasia (L-CIGN) and adenocarcinoma in situ (H-CGIN) in the same series. $^{59930}$ These studies have reported a difference of only one to three years in the mean age between low and high grade lesions. In this study we found a difference of four years. If the natural history follows this pattern, there seems to be a short clinical window for detecting early glandular lesions.

Whether all glandular precursor lesions eventually progress to invasive disease remains uncertain. In our study, the ratio of "precursor" lesions to invasive adenocarcinomas diagnosed in the same study period is nearly equal - that is, 1.12:1 (65:56). This is unlike its squamous counterpart in which CIN3 lesions far outnumber invasive disease by a ratio of approximately 15:1 (Al-Nafussi A, unpublished data). The other interesting finding was the ratio of microinvasive adenocarcinoma to H-CGIN. We found that $21 \%$ of the latter contained foci of early invasion. This is much less than reported by Teshima et $a l,{ }^{25}$ who showed that 22 of 30 cases of adenocarcinoma in situ $(73 \%)$ had features of early invasion. It is also of interest that in our study the mean age of women with both high grade and microinvasive adenocarcinoma was the same (43 years), while in Teshima's series there was a difference of six years. This difference in age groups between the two studies might explain the variation in our findings. From these observations, it appears that high grade CGIN is almost certainly a precursor of invasive adenocarcinoma, in view of the high percentage of early invasion coexisting with high grade lesions.

As to the natural history of L-CGIN, it is not clear whether all or some would eventually progress to high grade or invasive adenocarcinoma. From our observation it appears that such lesions may progress to H-CGIN or even to invasive disease-first, because of the 
presence of low grade lesions in association with high grade lesions and microinvasive adenocarcinoma; second, because of the age difference of four years between the low and the high grade lesions; and third, because the ratio between L-CGIN and H-CGIN in our study was $0.96: 1$ (27:38). If low or high grade lesions often regress, one would expect to see them more often in the many cervical biopsies we encounter every day, though it is possible that some low grade lesions may be missed or be misinterpreted as benign non-neoplastic processes such as tuboendometrial metaplasia or mesonephric duct remnants. ${ }^{34}$ In support of progression, Umezaki et al showed that there was expression of epithelium specific antigen (ESA; a useful marker of endocervical glandular dysplasia and related lesions with malignant transformation) in over half the endocervical dysplasia specimens they examined. ${ }^{35}$ This rate of expression was similar to that seen in most of the cervical adenocarcinomas they studied..$^{35}$

There is currently no standard treatment for precursor glandular lesions. Whether cervical conisation alone is therapeutic is still controversial. One reason for this controversy is the presence of residual disease in hysterectomy specimens, following what appeared to be complete loop or cone excisions of H-CGIN (adenocarcinoma in situ). ${ }^{32} 33$ 36-47 The incidence of residual H-CGIN (adenocarcinoma in situ) in hysterectomy specimens following cone excisions with involved margins has been calculated to be approximately $60 \%{ }^{33}$ Furthermore, occult invasive carcinoma has also been detected in such cases. ${ }^{33}{ }^{36-47}$ In our study, residual disease was found in $43 \%, 50 \%$, and $33 \%$ of hysterectomies for L-CGIN, H-CGIN, and microinvasive adenocarcinoma, respectively. This high rate of residual disease occurred particularly in those cases with positive margins on previous loop excisions. Residual disease was similarly seen in one of our cases of H-CGIN with clear margins. This is not surprising considering the frequent multifocal nature of CGIN detected in this study, and the size of the loop excision procedure compared with cold knife conisation. It has been shown that conisation is associated with a $33 \%$ rate of positive margins compared with $50 \%$ for large loop excision of the transformation zone (LLETZ). ${ }^{32}$ Similarly the disease recurrence rate is higher in patients treated with LLETZ (29\%) than in those treated by cone excision $(6 \%))^{32}$ This is unlike CIN lesions, in which the loop excision procedure appears to be as effective as conisation. ${ }^{46}$ Furthermore, Denehy et al have found that negative endocervical curettings and uninvolved cone margins in patients with cervical adenocarcinoma in situ did not exclude the presence of residual endocervical glandular disease in subsequent surgical specimens. ${ }^{47}$ They have suggested that conservative management and subsequent surveillance of adenocarcinoma in situ should be undertaken with caution. ${ }^{47}$ This is in contrast to a recent report by Houghton et $a l^{48}$ who studied 19 cases of adenocarcinoma in situ of the cervix that were initially treated by diathermy loop excision. They found no residual diseases in five of their cases in which further surgery was performed. They concluded that excision margin status does not appear to be predictive of residual disease.

The cytological features of glandular neoplasia have been refined recently. ${ }^{611} 1^{150}{ }^{49-52}$ In our study, in those women who had smears before diagnosis, $59 \%, 70 \%, 100 \%$, and $32 \%$ of low grade CGIN, high grade CGIN, microinvasive adenocarcinoma, and frankly invasive adenocarcinoma, respectively, were predicted by cytology. Luesley et al reported that $71 \%$ of their cases had at least one cervical smear suggesting glandular abnormality in the preceding 12 months. ${ }^{9}$ Widrich et al reported that 19 of 45 cases of adenocarcinoma in situ $(42 \%)$ had glandular abnormality on smear test, ${ }^{30}$ while Casper et al reported that only $23 \%$ of low grade CGIN were screen detected. ${ }^{21}$ As in previous reports, ${ }^{52}$ a significant proportion of our cases $(30 \%$ of L-CGIN, $24 \%$ of H-CGIN, and $7 \%$ of invasive adenocarcinoma) were discovered incidentally at loop excision for CIN or at hysterectomy for benign lesions. Squamous abnormality on cervical smears may often overshadow coexisting glandular lesions. ${ }^{8} 93031$ The presence of mixed squamous and glandular lesions occurs in $49 \%$ to $69 \%$ of cases. $^{9} 214849$ In our study coexisting CIN was found in $55 \%$ of L-CGIN cases, $47 \%$ of H-CGIN cases, $40 \%$ of microinvasive adenocarcinomas, and $11 \%$ of invasive adenocarcinomas. This is in keeping with the theory of a unicellular origin and common aetiological factors for both lesions. ${ }^{53-57}$ Whatever the cause of this association, it seems to enable a significant number of cases of CIGN to be discovered that would otherwise have presented as invasive disease.

The cases in our study span 1990 to 1995 , limiting full five year follow up on later cases. We regarded a successful outcome as those cases with multiple negative smears following treatment (four to nine negative smears). In the great majority of our cases (all the L-CGIN cases, $95 \%$ of the H-CGIN cases, and all the microinvasive adenocarcinomas) there was no glandular abnormality on follow up. However, squamous dysplasia/dyskaryosis was detected in $15 \%$ and $2 \%$ of treated low grade and high grade CGIN cases, respectively.

Microinvasive adenocarcinomas in this study behaved like H-CGIN. This in keeping with previous reports. ${ }^{22}{ }^{24}$ Eight of our microinvasive adenocarcinomas (80\%) were stage $1 \mathrm{~A} 1$ (less than $3 \mathrm{~mm}$ in depth). This is slightly higher than the figures of $50 \%$ and $55 \%$ reported by Teshima et al and Ostor et $a l^{23}{ }^{25}$ but the numbers are small.

\section{CONCLUSIONS}

The results of this study support the view that there is a progression of L-CGIN and $\mathrm{H}-\mathrm{CGIN}$ to early stromal invasion and eventually to frankly invasive disease. The evidence for this is the progressive increase in mean age of patients from "precursor lesions" to invasive adenocarcinoma, the high incidence of microinvasive adenocarcinoma in association with 
$\mathrm{H}-\mathrm{CGIN}$, and the near equal ratio between non-invasive and invasive disease. This progression perhaps takes place within 10 years or less. In the management of precursor lesions we strongly recommend a large loop excision with free margins in patients who are not treated by hysterectomy. Finally we endorse the use of the term "microinvasive adenocarcinoma" as a distinct entity, as it has an excellent prognosis if treated by hysterectomy.

1 Stockton D, Cooper P, Lonsdale RN. Changing incidence of invasive adenocarcinoma of the uterine cervix in East Anglia. f Med Screen 1997;4:40-3.

2 Parazzini F, La Vecchia C. Epidemiology of adenocarcinoma of the cervix. Gynecol Oncol 1990;39:40-6.

3 Leminen A, Paavonen J, Forss M, et al. Adenocarcinoma of the uterine cervix. Cancer 1990;65:53-9.

4 Al-Nafussi A, McGoogan E. Auditing the smear histories of women with invasive cervical cancer for the years 1993 , 1994, and 1995 in South East of Scotland [abstr] Cytopathology 1996;1 (suppl 1):7.

5 Cullimore JE, Luesley DM, Rollason TP, et al. A prospective study of conization of the cervix in the management of cervical intraepithelial glandular neoplasia (CIGN) - a preliminary report. Br J Obstet Gynaecol 1992;99:314-18.

6 Anderson MC. Glandular lesions of the cervix: diagnostic and therapeutic dilemmas. Baillieres Clin Obstet Gynaecol 1995;9:105-19.

7 Gloor E, Hurlimann J. Cervical intra-epithelial glandular neoplasia (adenocarcinoma in situ and glandular dysplasia). Cancer 1986;58:1272-80.

8 Brown JLR, Wells M. Cervical glandular atypia associated with squamous intraepithelial neoplasia: a premalignant lesion? ₹ Clin Pathol 1986;39:229-9.

9 Luesley DM, Jordan JA, Woodman CBJ, et al. A retrospective review of adenocarcinoma-in situ and glandular atypia of the uterine cervix. Br f Obstet Gynaecol 1987;94:699703 .

10 Anderson MC, Fox H, Wells M, et al. Premalignant and malignant glandular lesions of the cervix. In: Haines and Taylor obstetrical and gynecologic pathology. New York: Churchill-Livingstone, 1995:273-364.

11 Biscotti CV, Gero MA, Toddy SM, et al. Endocervical adenocarcinoma in situ: an analysis of cellular features. Diagn Cytopathol 1997;17:326-32.

12 Jaworski RC. Endocervical glandular dysplasia, adenocarcinoma in situ, and early invasive (microi cinoma of the uterine cervix. Diagn Pathol 1990;7:190-204.

13 Scully RE, Bonfiglio TA, Kurman RJ, et al. Histological typing of female genital tract tumours. WHO International histological classification of tumours, 2nd ed. Geneva: World Health Organisation, 1994: 43-4

14 Boon ME, Baak JPA, Kurver PJH, et al. Adenocarcinoma in situ of the cervix: an underdiagnosed lesion. Cancer 1981;48:768-73.

15 Young RH, Clement PB, Scully RE. Premalignant and malignant glandular lesions of the uterine cervix. In: Clement PB, Young RH, eds. Tumors and tumor like lesions of the ent PB, Young RH, eds. Tumors and tumor like lesions of the 1993.

16 Gloor E, Ruzicka J. Morphology of adenocarcinoma in situ of the uterine cervix: a study of 14 cases. Cancer 1982;49:294-302

17 Boddington MM, Spriggs AI, Cowdell RH. Adenocarcinoma of the uterine cervix: cytological evidence of a long preclinical evolution. Br f Obstet Gynaecol 1976;83:900-3.

18 Kashimura M, Shinohara M, Oikawa K, et al. An adenocarcinoma in situ of the uterine cervix that developed into invasive adenocarcinoma after 5 years. Gynecol Oncol 1990; 36:128-33.

19 Cullimore JE, Luesley DM, Rollason TP, et al. A case of glandular intraepithelial neoplasia involving the cervix and vagina. Gynecol Oncol 1989;34:249-52.

20 Hunter RW, Hammond IG. A case of multicentric glandular tumorigenesis of the female upper genital tract. Aust NZ $\mathscr{F}$ Obstet Gynaecol 1993;33:333-4.

21 Casper GR, Ostor AG, Quinn MA. a clinicopathologic study of glandular dysplasia of the cervix. Gynecol Oncol study of glandular

22 Mulvany N, Ostor A. Microinvasive adenocarcinoma of the cervix: a cytohistopathologic study of 40 cases. Diagn Cytopathol 1997;16:430-6.

23 Ostor A, Rome R, Quinn M. microinvasive adenocarcinoma of the cervix: a clinicopathologic study of 77 women. Obstet Gynecol 1997;89:88-93.

24 Nakamima H. A clinicopathological study of early adenocarcinoma of the uterine cervix. Nagasaki Med F 1983;58: 218-33.

25 Teshima S, Shimosato Y, Kishi K, et al. Early stage adenocarcinoma of the uterine cervix: histopathologic analysis with consideration of histogenesis. Cancer 1985;56: $167-72$.
26 Kaspar HG, Tung VD, Doherty MG, et al. Clinical implications of tumour volume measurement in stage I adenocarcinoma of the cervix. Obstet Gynecol 1993;81:296-9.

27 Hoking GR, Hayman JA, Ostor AG. Adenocarcinoma in situ of the uterine cervix progressing to invasive adenocarcinoma. Aust NZ F Obstet Gynaecol 1996;36:167-72.

28 Rollason TP, Cullimore J, Bradgate MG. A suggested columnar cell morphological equivalent of squamous carcinoma in situ with early stromal invasion. Int f Gynecol Pathol 1989;8:230-6.

29 Cancer Committee of FIGO. Staging announcement. Gynecol Oncol 1986;25:383-5.

30 Bousfield L, Pacey F, Young Q, et al. Expanded cytological criteria for the diagnosis of adenocarcinoma-in-situ of th cervix and related lesions. Acta Cytol 1980;24:283-95.

31 Christopherson WM, Nealon N, Gray LA. Non-invasive precursor lesions and adenocarcinoma and mixed adenosquamous carcinoma of the cervix uteri. Cancer 1979;44: 975-83.

32 Widrich T, Kennedy AW, Myers TM, et al. Adenocarcinoma in situ of the uterine cervix: management and outcome. Gynecol Oncol 1996;61:304-8.

33 Howard G, Muntz HG. Can cervical adenocarcinoma in situ be safely managed by conization alone? Gynecol Oncol 1996;61:301-3.

34 Young RH, Clement PB. Pseudoneoplastic glandular lesions of the uterine cervix. Semin Diagn Pathol 1991;8:234-49.

35 Umezaki K, Sanezumi M, Okada H, et al. Distribution of epithelial-specific antigen in uterine cervix with endocervical glandular dysplasia. Gynecol Oncol 1997;66:393-8.

36 Widrich T, Kennedy AW, Myers TM, et al. Adenocarcinoma in situ of the uterine cervix: management and outcome. in situ of the uterine cervix:

37 Bertrand M, Lickrish GM, Colgan TJ. The anatomic distribution of cervical adenocarcinoma in situ: implications for treatment. Am f Obstet Gynecol 1987;157:21-5.

38 Ostor AG, Pagano R, Davoren RAM, et al. Adenocarcinoma in situ of the cervix. Int J Gynecol Pathol 1984;3:179-90.

39 Nicklin JL, Wright RG, Bell JR, et al. A clinicopathological study of adenocarcinoma in situ of the cervix. The influence of cervical HPV infection and other factors, and the role of conservative surgery. Aust NZ F Obstet Gynaecol 1991;2:179-83.

40 Muntz HG, Bell DA, Lage JM, et al. Adenocarcinoma in situ of the uterine cervix. Obstet Gynecol 1992;80:935-9.

41 Qizilbash AH. In-situ and microinvasive adenocarcinoma of the uterine cervix. A clinical, cytologic and histologic study of 14 cases. Am J Clin Pathol 1975;64:155-70.

42 Hopkins MP, Roberts JA, Schmidt RW. Cervical adenocarcinoma in situ. Obstet Gynecol 1988;71:842-4.

43 Andersen EA, Arffmann E. Adenocarcinoma in situ of the uterine cervix: a clinico-pathologic study of 36 cases. Gynecol Oncol 1989;35:1-7.

44 Poynor EA, Baraket RR, Hoskins WJ. Management and follow-up of patients with adenocarcinoma in situ of the uterine cervix. Gynecol Oncol 1995;57:158-64.

45 Im DD, Duska LR, Rosenshein NB. Adequacy of conization margins in adenocarcinoma in situ of the cervix as a predictor of residual disease. Gynecol Oncol 1995;59:17982.

46 Gold M, Dunton CJ, Murray J, et al. Loop electrocautery excisional procedure: therapeutic effectiveness as an ablation and a conization equivalent. Gynecol Oncol 1996;61:241-4

47 Denehy TR, Gregori CA, Breen JL. Endocervical curettage, cone margins, and residual adenocarcinoma in situ of the cervix. Obstet Gynecol 1997;90:1-6

48 Houghton SJ, Shafi MI, Rollason TP, et al. Is loop excision adequate primary management of adenocarcinoma of the cervix? Br J Obstet Gynaecol 1997;104:325-9.

49 Keyhani RS, Brewer J, Prokorym P. Comparative cytologic findings in situ and invasive adenocarcinoma of the uterine cervix. Diagn Cytopathol 1995;12:120-5.

50 Laverty CR, Farnsworth A, Thurloe J, et al. The reliability of a cytological prediction of cervical adenocarcinoma in situ. Aust NZ F Obstet Gynaecol 1988;28:307-11.

51 Siziopikou KP, Wang HH, Abu-Jawdeh G. Cytologic features of neoplastic lesions in endocervical glands. Diagn Cytopathol 1997;17:1-7.

52 Jackson SR, Hollingworth TA, Anderson MC, et al. Glandular lesions of the cervix - cytological and histological correlation. Cytopathology 1996;7:10-16.

53 Brinton LA, Herrerro R, Reeves WC, et al. Risk factors for cervical cancer by histology. Gynecol Oncol 1993;51:301-6.

54 Pickel H. Adenocarcinoma in situ of the uterine cervix. Arch STD/HIV Res 1994;8:189-98.

55 Duggan MA, McGregor SE, Benoit JL, et al. The human papillomavirus status of invasive cervical adenocarcinoma: a clinicopathological and outcome analysis. Hum Pathol 1995;26:319-25.

56 Yamakawa Y, Forslund O, Teshima H, et al. Human papillomavirus DNA in adenocarcinoma and adenosquamous carcinoma of the uterine cervix detected by polymerase chain reaction (PCR). Gynecol Oncol 1994;53:190-5.

57 Parazzini F, La Vecchia C. Epidemiology of adenocarcinoma of the cervix. Gynecol Oncol 1990;39:40-6. 